\section{Refazendo a Fábrica Fordista}

\section{Elizabeth Bortolaia Silva}

São Paulo, Editora Hucitec, Fundação de Amparo à Pesquisa do Estado de São Paulo, 1991, 394 páginas.

Por Claưde Machline, Professor Titular do Departamento de Administração de Produção, Logística e de Operações Industriais da EAESP/FGV.

- lizabeth Bortolaia Silva é doutora em Sociologia Industrial pelo Imperial College of Science and Technology da Universidade de Londres. E graduada em Ciências Sociais e Mestre em Ciência Política pela Universidade de São Paulo.

A autora aborda no seu livro temas de extremos interesse e relevância, notadamente a relação entre tecnologia e organização do trabalho; a influência da automação sobre produtividade e qualidade; e as pressões da competição nacional e internacional, que compelem a fábrica a se adequar aös seus novos desafios.

A análise baseia-se numa comparação entre duas fábricas de automóveis, uma inglesa, localizada em Dagenham, Essex, na Grã-Bretanha, e outra, brasileira, situada em São Bernardo do Campo, na Grande São Pau1o. Ambas as unidades pertencem à Ford Motor Company. A pesquisa foi realizada em 1986, para elaboração da tese de doutorado da autora.

O texto é dividido em dez capítulos. No primeiro, é passada em revista a literatura sobre o tema, citando-se os trabalhos clássicos de Joan F. Woodward e Michel Crozier. Esses representantes do "determinismo tecnológico" argumentam que uma única forma de organização é mais apropriada para os requerimentos tecnológicos de cada estágio de desenvolvimënto econômico. A escola oposta, de "determinismo cultural", representada por Duncan Gallie e Ian Maitland, sustenta que a cultura nacional determina o uso da tecnologia, a organização do trabalho e as estratégias de gerenciamento, negando a existência de correlação entre tecnologia e trabalho. É apresentada ainda a perspectiva da moderna "escola da regulação", que postula a existência de uma lógica universal de trabalho, mas afirma que cada sociedade gera seu próprio processo de adaptação e mudança a partir de capacidades e recursos próprios.

Ainda neste primeiro cápítulo, examina-se outro fator preponderante que modifica as condições sociais de produção: o padrão dominante de produção na época, que é, hoje, o modelo japonès. O profundo impacto das práticas japonesas, disseminadas universalmente, tais como círculos de controle de qualidade, qualidade total, participação, células de fabricação, just in time, kan- ban, polivalência, auto-regulação, e controle estatístico do processo, é lembrado como um fator decisivo na escolha da empresa ocidental por determinado tipo de organização do trabalho.

A competição nacional e internacional é discutida nos capítulos 2 e 3 . É determinante essencial da tecnologia a ser adotada, visando sobretudoà melhoria da qualidade e à redução dos custos, pois a empresa deve, sob ameaça de falência, impor aos seus empregados novas tecnologias e formas de organização do trabalho, para sobreviver, lembra-nos a autora.

O Capítulo 4 focaliza as estratégias e estruturas da Ford Motor Company nos últimos cinqüenta anos.

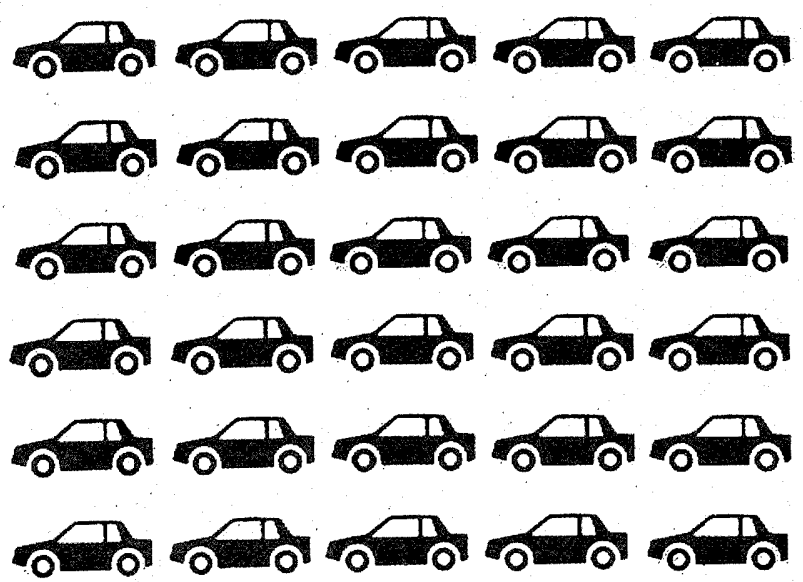

No Capítulo 5 , após tecer consideraçôes sobre as dificuldades de se efetuar comparações de produtividade entre empresas, descrevem-se em minúcias as mudanças introduzidas nas fábrieas de Dagenham e São Bernardo, para modernizá-las. Semelhanças e diferenças entre as opções escolhidas, aqui e lá, nos processos de produção, setor por setor, são descritas e comentąas.

Os três capítulos seguintes examinam os sistemas de relăções industriais na Grä-Bretanha e no Brasil, com ênfase no segmento automobilístico, e, em particular, na Ford.

O Capítulo 9 analisa a flexibilidade, qualidade e eficiència nas duas fábricas, mostrando que Dagenham optou por se modernizar, atualizando seu plano de cargos, carreira e salários, enquanto São Bernardo adotou as práticas de Trabalho Participativo (Employee Involvement). A autora constata que o Brasil possui melhores condições para se valer da participação no trabalho do que a Inglaterra, que possui maior tradição sindical, ainda que na Europa tenha nascido a idéia de participação.

O Capítulo 10 encerra a obra com o argumento de que diversidades nacionais e tradiçōes históricas condicionam as estratégias competitivas dos diversos países. O uso de tecnologia de ponta é apenas um fator, entre muitos, que pesará na estrutura organizacional e nos resultados econômicos. 
A comparação entre as duas fábricas deve ser entendida como sendo apenas um ponto de partida para o debate das momentosas questões levantadas nesta obra, pois, como lembra a autora, a complexidade dos fatores envolvidos leva a muita cautela nas conclusões. Vale, para o leitor brasileiro, a descrição pormenorizada da fábrica da Ford $\mathrm{ABC}$ e de seus esforços de inserção na modernidade. É fascinante o relato das agitações sindicais da última década. Mas as variáveis exôgenas são numerosas, complexas e excessivamente inter-relacionadas para que se possa extrair alguma conclusão válida sobre qual elemento (tecnologia, cultura, tradição, estratégias empresarial e sindical, estrutura salarial e outros) determinará de forma decisiva a organização do chão da fábrica.

Oque é uma "fábrica fordista"? E para que "refazer a fábrica fordista"? A planta gigante que Henry Ford I montou em Detroit, em 1908, é emblemática do processo industrial que estabeleceu a supremacia norte-americana neste século. Suas características principais são as seguintes, recorda a autora:

- produção em série, a custo mínimo;

- mercado de massa, economia de escala;

- padronização do produto;

- racionalização do trabalho, através do uso dos conceitos taylorianos, de procura da eficiência e de administração "científica";

- fragmentação das tarefas do trabalhador, levando à monotonia e ao alheiamento do operador, sobretudo na linha de montagem;

- utilização intensiva de assessorias, limitando a "linha" à execução rotineira dass operações.

O modelo japonês, cujo paradigma é a Toyota Motor Co., utilizou muitos princípios do fordismo, mas também se valeu dos ensinamentos das escolas de administração que sucederam ao taylorismo, como as de Relações Humanas e de Sistemas, além de se estribar em características culturais japonesas, tais como a disciplina, o senso do dever, a habilidade de trabalhar em equipes, o medo de perder a face e o emprego, o revanchismo, e assim por diante.

Para os gerentes industriais brasileiros, o fordismo, que, reconhece a autora, provavelmente nunca foi intensamente praticado no País, exceção feita a algumas grandes empresas de montagem, é considerado, de qualquer forma, superado, e nenhum deles se proporia a refazer uma fábrica fordista. O objetivo, hoje, é montar um sistema produtivo, econômico e de qualidade excelente, incorporando, na medida do possível, os procedimentos que estão dando certo no Japão, na Ásia e nos "transplantes" realizados em outros países. A automação, como qualquer outra técnica, será adotada caso se justifique economicamente ou por motivos de qualidade ou de melhoria da "imagem" da empresa no mercado externo.

O grande problema prático, para o administrador brasileiro, é a escolha do método a adotar para reduzir seus custos, melhorar sua qualidade e manter os prazos prometidos de entrega.

A leitura deste trabalho contribuirá para que o administrador nacional tenha sua escolha facilitada e o estudioso da economia e do trabalho entenda melhor as profundas alterações que estão ocorrendo em toda parte na tecnologia e na organização da fábrica, a ponto de serem consideradas, sob as designações de neofordismo, pósfordismo, ohnismo, toyotismo ou fujitsuísmo, conceitos radicalmente diferentes do fordismo do início do século.

Na fábrica moderna, os desvios mais momentosos em relação ao fordismo clássico são os seguintes: flexibilidade nos processos, a fim de fabricar gamas variadas de produtos, bastando mencionar que o moderno automóvel, longe de ser um "João ninguém" padronizadó, é fabricado sob encomenda, segundo as especificações de cada cliente; redução sempre maior do prazo de entrega; e papel cada vez mais abrangente do homem de linha, com o conseqüente declínio do assessor, provocando ingentes repercussões na organização do trabalho.

Em conclusão, o trabalho em tela, por sinal, de sólida estrutura e fina lavra, se não esgota o tema que se propôs abordar, nem valida qualquer hipótese, tem o mérito de apontar para o vasto espectro de fatores a influenciar a estruturação do trabalho na fábrica moderna, que está tendo efetivamente que ser produndamente "refeita", além do "fordismo". $\square$

\section{Negotiations: Varieties, Contexts, Processes and Social Order}

\section{Anselm Strauss \\ Londres, Jossey-Bass Publishers, 1978.}

Por Rơberto Venosa, Engenheiro, Mestre em Administração Pública pela Universidade de Pittsburgh, Doutor em Sociologia pela EHESS, Paris, professor Titular do Departamento de Administração Geral e Recursos Humanos da EAESP/FGV e professor visitante da University of St. Andrews, Escócia.

nselm Strauss, muito provavelmente, não é um autor nem suficientemente conhecido nem citado por aqueles que trabalham com Teoria Organizacional. No entanto, uma das preocupações de Strauss - negociação - começa a ser um tópico de 